\title{
Assassinato múltiplo: o que sabemos?
}

Multiple murder: what do we know?

Asesinato múltiple: ¿qué sabemos?

Saulo Maia Martins da Silva - https://orcid.org/0000-0003-0883-1012

Caio Gibaile Soares Silva - https://orcid.org/0000-0001-6223-541X

Bibiana de Borba Telles - https://orcid.org/0000-0002-0398-2412

Alcina Juliana Soares Barros - https://orcid.org/0000-0001-7936-0137

Lisieux Elaine de Borba Telles

- https://orcid.org/0000-0003-4105-

$\underline{5924}$

\section{RESUMO:}

Introdução: Um evento homicida com a presença de várias vítimas pode ser definido como um assassinato múltiplo, porém esse termo refere-se a uma categoria mais ampla que compreende as subclassificações: assassinato em massa, assassinato em série e assassinato relâmpago. Objetivo: Revisar as definições desses termos, abordando os aspectos psiquiátricos que podem estar presentes em cada um dos tipos de homicídio múltiplo, buscando atualizar a classe médica e os demais profissionais que trabalham com essa temática e instrumentalizar suas ações de investigação, avaliação e tratamento. Método: Revisão narrativa visando discutir o estado da arte e atualização do conhecimento sobre assassinato múltiplo. Discussão: A literatura aponta que assassinato em massa, assassinato em série e assassinato relâmpago possuem características específicas, que vão além do número de vítimas e compreendem as características psicopatológicas de seus perpetradores, desde a ausência de qualquer transtorno psiquiátrico até quadros de transtornos antissociais, narcisistas ou psicóticos. Conclusão: 
conhecimento de suas definições e particularidades possibilita o uso adequado dos termos, assim como auxilia o raciocínio diagnóstico acerca dos transtornos psiquiátricos que podem estar presentes nos criminosos que cometem tais atos.

Palavras chave: homicídio, crime, psicopatologia, transtorno de personalidade

\section{ABSTRACT:}

Introduction: A homicidal event with the presence of several victims can be defined as a multiple murder, but this term refers to a broader category that includes the sub-classifications: mass murder, serial murder and lightning murder. Objective: To review the definitions of these terms, addressing the psychiatric aspects that may be present in each type of multiple homicide, seeking to update the medical profession and other professionals who work with this theme and to implement their investigation, assessment and treatment actions. Method: Narrative review to discuss the state of the art and update knowledge on multiple murder. Discussion: The literature indicates that mass murder, serial murder and lightning murder have specific characteristics that go beyond the number of victims and include the psychopathological characteristics of their perpetrators, from the absence of any psychiatric disorder to antisocial and narcissistic disorders or psychotics. Conclusion: The knowledge of their definitions and particularities enables the proper use of terms, as well as aids diagnostic reasoning about psychiatric disorders that may be present in criminals who commit such acts.

Keywords: homicide, crime, psychopathology, personality disorder

\section{RESUMEN:}

Introducción: Un hecho homicida con presencia de varias víctimas puede definirse como homicidio múltiple, pero este término se refiere a una categoría más amplia que comprende las subclasificaciones: homicidio masivo, homicidio en serie y homicidio relámpago. Objetivo: Revisar las definiciones de estos términos, abordando los aspectos psiquiátricos que pueden estar presentes en cada tipo de homicidio múltiple, buscando 
actualizar la profesión médica y otros profesionales que trabajan con esta temática e implementar sus acciones de investigación, valoración y tratamiento. Método: Revisión narrativa para discutir el estado del arte y actualizar el conocimiento sobre asesinatos múltiples. Discusión: La literatura indica que los asesinatos masivos, los asesinatos en serie y los asesinatos relámpago tienen características específicas que van más allá del número de víctimas y comprenden las características psicopatológicas de sus perpetradores, desde la ausencia de algún trastorno psiquiátrico hasta los trastornos antisociales, narcisistas o psicóticos. Conclusión: El conocimiento de sus definiciones y particularidades permite el uso adecuado de los términos, así como ayuda al razonamiento diagnóstico sobre los trastornos psiquiátricos que pueden estar presentes en los delincuentes que com actos.

Palabras clave: homicidio, crimen, psicopatologia, trastorno de personalidad

Como citar: Silva S.M.M., Silva C.G.S., Telles B.B., Barros A.J.S., Telles L.E.B. - Assassinato múltiplo: o que sabemos? Debates em Psiquiatria, Rio de Janeiro, 2021; 11:1-22. https://doi.org/10.25118/27639037.2021.v11.273

Conflito de interesses: declaram não haver

Fonte de financiamento: declaram não haver

Parecer CEP: não se aplica

Recebido em: $13 / 11 / 2021$

Aprovado em: 14/11/2021

Publicado em: 16/11/2021

\section{Introdução}

Os homicídios representam um desafio para a ciência atual, tanto por sua alta prevalência, quanto pelas implicações destes atos para as vítimas, os agressores, as famílias dos envolvidos e a sociedade. Os psiquiatras podem 
colaborar para o entendimento e prevenção deste fenômeno, através do estudo e da avaliação dos agressores e na designação do tratamento adequado, quando há algum transtorno psiquiátrico envolvido. O termo homicídio abrange toda forma de morte violenta pela qual a vida de uma pessoa é tomada por outra em um contexto de poder, ganho pessoal, brutalidade e por vezes sexualidade, suas graves implicações tornam sua detecção, solução e julgamento questões de importância vital para cada cidadão e para toda a sociedade $[\underline{1}, \underline{2}]$.

A categorização dos homicídios de acordo com suas semelhanças possibilita o estudo de suas características e, consequentemente, uma melhor compreensão dos comportamentos, motivações e psicopatologia dos indivíduos que cometem esses crimes. A ocorrência de homicídios que envolvem várias vítimas é considerada rara e difícil de ser prevista, porém quando estes eventos ocorrem são amplamente divulgados pela mídia e causam uma mistura de horror e fascinação na sociedade. [1]

Criminosos que causam a morte de um grande número de vítimas, seja uma por vez, ou atirando de modo indiscriminado em locais públicos, também despertam a atenção dos psiquiatras que buscam compreender e auxiliar na avaliação e prevenção destes eventos [ㅍ].

Os homicídios com múltiplas vítimas podem ser classificados de diversas formas e, por vezes, os termos "assassinato múltiplo" (multiple murder), "assassinato em massa" (mass murder) e "assassinato em série" (serial killer), são incorretamente usados como sinônimos, contudo, cada uma dessas expressões guarda características específicas, não apenas em 4 Debates em Psiquiatria, Rio de Janeiro, 2021; 11:1-22 https://doi.org/10.25118/2763-9037.2021.v11.273 
relação ao número de vítimas, mas também em relação aos atributos de seus causadores, suas psicopatologias e motivações.

Estudos acerca de homicídios buscam formular classificações com base nos tipos de personalidade, a relação entre o perpetrador e a vítima, as circunstâncias do evento ou categorias legais. Uma visão contemporânea amplamente aceita é de que existem três formas principais de assassinato múltiplo: o assassinato em massa, o assassinato em série e o assassinato relâmpago $[\underline{3}, \underline{4}, \underline{5}]$.

Esse artigo se propõe a revisar as definições desses termos, abordando os aspectos psiquiátricos que podem estar presentes em cada um dos tipos de homicídio múltiplo, buscando atualizar a classe médica e os demais profissionais que trabalham com essa temática e instrumentalizar suas ações de investigação, avaliação e tratamento.

\section{Conceitos}

A Unidade de Ciências Comportamentais do FBI (Federal Bureau of Investigation), órgão policial do Departamento de Justiça dos Estados Unidos, iniciou sua contribuição para a categorização dos homicídios em 1980, a partir de uma publicação sobre assassinos envolvidos em crimes sexuais. Em 1986, Douglas, Ressler, Burges e Hartman [ㅁ] , publicaram uma classificação que é usada até o presente para a categorização dos tipos de homicídio, sendo feita de acordo com o número, o tipo e a forma da morte.

A definição dos homicídios pelo número de vítimas é uma das principais formas de referir-se a esse tipo de crime, dessa forma, um homicídio único 
é definido pela existência de uma única vítima. Um homicídio duplo ocorre quando duas vítimas são mortas em mesmo evento, e um homicídio triplo é caracterizado pela presença de três vítimas em um mesmo evento [4]. Um evento homicida com a presença de múltiplas vítimas pode ser descrito como um assassinato múltiplo, o qual compreende os assassinatos em massa, os assassinatos em série e os assassinatos relâmpago $[\underline{3}, \underline{5}]$, cada um desses termos guarda características específicas em relação ao ato homicida em si e ao seu perpetrador, e não devem ser usados como sinônimos.

\section{Assassinato em massa}

A presença de várias vítimas em um único local e em um mesmo evento é descrita como um assassinato em massa (mass murder) [ㄴ, $\underline{7}]$. O número exato de vítimas necessário para caracterizar este tipo de homicídio é arbitrário, com algumas autoridades sugerindo quatro vítimas, enquanto outras sugerem o número mínimo de três.

Para o autor Michael D. Kelleher [] $]$, a intenção de um indivíduo de causar múltiplas fatalidades é o elemento mais importante para a classificação de assassinatos em massa, em detrimento de uma categorização baseada meramente na contagem do número de vítimas. Os assassinos em massa podem ser subdivididos em categorias de acordo com suas motivações e psicopatologia em: discípulos, aniquiladores familiares, pseudocomandos e funcionários descontentes $\mathrm{e}$, independentemente do subtipo, a característica fundamental desses perpetradores é o ódio e a raiva, geralmente, estes indivíduos sentem que não foram tratados com justiça, 
de modo que a vingança é muitas vezes o motivo principal para o ato homicida []ㅜ.

Os tiroteios em escolas, universidades e locais de trabalho são frequentemente associados aos Estados Unidos, no entanto, estes eventos afetam vários países em todo o mundo, incluindo o Brasil. Apesar dos assassinatos em massa terem começado a ser relatados na sociedade ocidental a partir do século XX, outras culturas têm falado de incidentes semelhantes desde o século XVI [10] .

O risco de ocorrência desses eventos parece ser mediado por uma interação complexa de vários fatores, entre eles: a mídia, o acesso a armas e a migração [11]. Países com leis de controle de armas de fogo mais brandas têm um risco maior de assassinatos em massa, quando comparados àqueles com legislações de controle mais rígidas [12]. Apesar dos assassinatos em massa serem considerados eventos infrequentes, quando ocorrem são exaustivamente explorados por noticiários, revistas e jornais, dessa forma, há uma crença que essa ampla divulgação pode ajudar a enaltecer esse tipo de crime e recompensar indiretamente o assassino, ajudando-o a alcançar o "martírio", além de aumentar a probabilidade de imitações por indivíduos que se identificam com os ideais, crenças ou estados emocionais do criminoso, em um fenômeno chamado

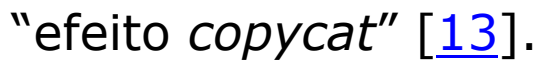

A influência da migração como um fator contribuidor para esses atos de violência é controversa, com poucos autores abordando este fator. De acordo com Lee (2007) [14], a migração se relaciona com os assassinatos em massa pelas condições adversas a que pode expor o imigrante, devido 
a mudanças no ambiente social, nas relações interpessoais e diferenças culturais e, dessa forma segundo Lee [14]: "Um imigrante teria mais probabilidade de sentir-se alienado e mais predisposto a sentimentos de paranoia. Esta intolerância de indivíduos pela sociedade em geral é um terreno fértil para sentimentos de alienação, perseguição e um senso de "alteridade", permitindo assim que se tornem mais suscetíveis a externalizar a culpa e a raiva pelos muitos obstáculos e dificuldades que Ihes são impostos".

Apesar dos afetos de fúria, raiva e ódio, os assassinatos em massa não costumam ocorrer de modo impulsivo, ao contrário, costumam ser planejados com ampla antecedência e de forma metódica. O local, as vítimas, as vestimentas e as armas que serão usadas são selecionadas e adquiridas com antecedência e, com frequência, o assassino menciona antecipadamente seus planos e ameaças - "leakage" - antes de realizar o ataque.

O'Toole [15] foi a primeira autora a conceituar o termo leakage em um contexto de avaliação de ameaças a escolas, definindo como:

"quando um estudante intencionalmente ou não, revela pistas sobre seus sentimentos, pensamentos, fantasias, atitudes ou intenções que podem sinalizar um ato violento iminente. Essas pistas podem assumir a forma de ameaças sutis, insinuações, previsões ou ultimatos. As pistas podem ser faladas ou transmitidas em histórias, diários, ensaios, poemas, cartas, canções, desenhos, rabiscos, tatuagens ou vídeos". 
Estudos têm mostrado que terceiros, em até $75 \%$ das vezes, têm conhecimento de ameaças específicas ou generalizadas acerca do plano do atirador, sendo que os adolescentes comunicam suas intenções antes do evento mais frequentemente do que os adultos $[\underline{15}, \underline{16}]$.

Em outras ocasiões de assassinatos em massa, os homicídios podem ser o resultado de delírios ou alucinações e, nestes casos, o assassino não age, em resposta à raiva, ódio ou ressentimento, mas sim, seu ato é uma resposta a um quadro psicótico [17].

A mídia aborda com frequência o papel da psicose nos assassinatos em massa, relacionando os quadros psicóticos com esses eventos. No entanto, enquanto é plausível que a maioria dos assassinos em massa possa apresentar transtornos psiquiátricos [16], é raro que apresentem psicose, pois observa-se que quanto mais específicos os alvos do homicídio em massa, menos provável que o perpetrador seja psicótico, pois em essência, a psicose dificultaria uma forma de planejamento mais elaborado [1ㄹ] .

O caso do estudante da Universidade Virginia Tech, ilustra este tipo de assassinato, em 16 de abril de 2007, Seung Hui Cho, abriu fogo no campus de sua universidade matando 33 estudantes e ferindo outros 24. Após o ato homicida, Cho cometeu suicídio com uma arma de fogo. $O$ estudante era acompanhado pela polícia desde o final 2005, devido a condutas ameaçadores à professores e a outros estudantes, tendo passado por avaliação psicológica e um período em observação em uma unidade de saúde mental. No dia de seu ataque à Universidade, Cho enviou uma série de fotos nas quais aparece em trajes militares e armado com pistolas e metralhadoras para uma rede de televisão, além de um manifesto 
explicando seus motivos para o ataque. Nesse material o assassino expressa o seu ressentimento com seus colegas, sua percepção de ter sido injustiçado e se refere aos maus tratos pelos quais teria passado. Por fim, projeta-se como um herói pelo ato que iria cometer $[\underline{14}, \underline{18}]$.

\section{Assassinato em série}

O termo "serial killer" é recente, remontando a década de 70, porém encontra-se referência a ocorrência desde tipo homicídio desde à Antiguidade. O político romano Lucius Calpurnius Bestia, foi acusado pela morte de várias de suas esposas por meio do uso de acônito, uma planta da qual se extrai um veneno letal, que segundo seus acusadores, ele inseria manualmente na vagina de suas vítimas durante o ato sexual. Em 69 d.C. Locusta, uma envenenadora de aluguel, foi executada publicamente por ordem do imperador romano Galba, pela morte de inúmeras vítimas $[\underline{10}, \underline{19}]$.

A definição precisa do termo assassinato em série é alvo de discussão na comunidade científica, porém, uma das definições mais aceitas é a presente no Manual de Classificação de Crimes (Crime Classification Manual, 2006), que compreende a ocorrência de: (i) ao menos duas vítimas (algumas definições requerem três vítimas); (ii) as vítimas são mortas de uma maneira não contínua (há um período de "esfriamento emocional" entre os assassinatos); e (iii) os assassinatos geralmente envolvem um forte componente sexual $[\underline{3}, \underline{4}]$.

O assassinato em série é, na maioria das vezes, um crime premeditado que envolve fantasia referente ao ato e planejamento meticuloso da escolha da vítima, local, situação e data. Após o crime, o assassino entra 
em um período chamado de "esfriamento emocional", que pode durar por horas, dias, meses, anos ou até mesmo ser permanente e, de acordo com Ressler e colaboradores [4] , é uma característica chave que distingue os assassinos em série dos outros assassinatos com múltiplas vítimas.

Os assassinos em série podem ser divididos nos subtipos organizado/compulsivo ou desorganizado/catatímico [20].

O primeiro compreende os assassinos em série que possuem boas habilidades verbais e sociais, são razoavelmente inteligentes, podem ter família e emprego, selecionam com antecedência suas vítimas e possuem características de sadismo sexual e personalidades antissocial e narcisista. Caracteristicamente apresentam distanciamento emocional da vítima e hiporreatividade autonômica.

O segundo subtipo abrange os assassinos em série que apresentam habilidades sociais empobrecidas e inteligência abaixo da média, são solitários, desempregados ou possuem subempregos, seus crimes ocorrem sem ou com pouco planejamento e costumam atacar de surpresa, aproveitando-se de uma oportunidade. Este subgrupo pode possuir diagnósticos de transtornos de humor e traços de personalidade variáveis, assim como hiper-reatividade autonômica e passado de abusos [21].

Esses dois subtipos representam dois extremos e um assassino em série pode estar em qualquer posição entre esses dois polos []]. Apesar da prevalência de assassinos em série ser predominantemente masculina, serial killers do sexo feminino representam um grupo importante e 
possuem características específicas que as diferenciam dos assassinos em série do gênero masculino.

O emprego de métodos violentos é menos frequente nesse grupo, onde é percebido com maior frequência o uso da asfixia e do envenenamento como forma de levar a vítima à morte, sendo que o uso destes artifícios pode dificultar a identificação do crime, podendo este ser, até mesmo, confundido com uma morte por causas naturais [르, 23] .

Assassinos em série atraem grande atenção da mídia e da comunidade em geral, porém, são raros e, dessa forma, os achados psiquiátricos dessa população são provenientes, principalmente, de estudos de caso e análises retrospectivas. Características frequentes compreendem um engajamento precoce em atividades criminais e crueldade com animais na infância [24]. Transtornos de personalidade, principalmente o antissocial e narcisista também são frequentes nestes indivíduos.

Outros transtornos psiquiátricos que podem estar presentes incluem as parafilias, traços obsessivo-compulsivos e déficits do neurodesenvolvimento.

A biografia de Jeffrey Dahmer, apresenta algumas características clássicas encontradas no histórico de assassinos em série. Filho de pais em constante conflito, aos 10 anos de idade Dahmer, que posteriormente seria conhecido como "o canibal de Milwaukee", realizava experiencias com animais mortos, como decapitar roedores e dissolver animais em ácido. Aos 18 anos, em 1978, Dahmer cometeu seu primeiro assassinato, tendo 
desmembrado e enterrado o corpo da vítima. Após passagens fracassadas pela universidade e pelo exército, Dahmer se estabeleceu em Milwaukee, no estado do Wisconsin, onde passou a colocar em prática suas fantasias de ter um parceiro sexual inteiramente a sua disposição. Além de estuprar, assassinar e esquartejar suas vítimas, acredita-se que Dahmer também tenha praticado atos de canibalismo com pelo menos um cadáver. Em 15 de fevereiro de 1992, Dahmer foi considerado culpado pelo assassinato de quinze homens, lhe sendo imposto quinze sentenças consecutivas de prisão perpetua. Jeffrey Dahmer morreu na prisão em 1994, após ser atacado por outro prisioneiro [르].

\section{Assassinato relâmpago}

O assassinato relâmpago (spree killer) é definido como um evento único em que ocorrem mortes em dois ou mais locais, sem um período de esfriamento emocional entre os incidentes [4]].

Um exemplo característico deste tipo de homicídio é o caso de Charles Whitman, que na noite de $1^{\circ}$ de agosto de 1966, dirigiu-se até o apartamento de sua mãe, onde a matou a tiros, retornou para sua residência e esfaqueou sua esposa até a morte. Posteriormente saiu de casa e escalou a torre do relógio da Universidade do Texas, onde começou a atirar nas pessoas que passavam pelo local das 11:45 até às 13:20. Desta torre, ele matou mais 15 pessoas [26]. O evento homicida, neste caso, durou quase um dia, mas como não houve um período de esfriamento emocional entre os assassinatos, e esses ocorreram em locais diferentes, este crime é classificado como um assassinato relâmpago. 
Há outras diferenças que auxiliam a distinguir os assassinatos em massa, assassinatos em série e assassinatos relâmpago. Além do número de vítimas, locais e presença ou ausência de um período de esfriamento emocional, os assassinos em massa e relâmpago estão dispostos a matar qualquer um que cruze seu caminho durante seu ataque [4]. Diferentemente, os assassinos em série selecionam cuidadosamente suas vítimas e acreditam que não serão pegos pelos seus crimes, seus passos são planejados e tentam manter-se fora do alcance das autoridades, controlando o fluxo de informações e, por vezes, "jogando" com estas. A partir do início de seus ataques, os assassinos em massa e relâmpago costumam ser rapidamente identificados e perseguidos pelas autoridades, perdendo o controle da situação que, com frequência, termina em um ato suicida, em uma última tentativa de controlar o curso dos eventos.

\section{Discussão}

A literatura que trata da tipologia de homicídios múltiplos apresenta discrepâncias quanto ao número de vítimas necessário para caracterizar um determinado tipo de crime, o local em que o evento ocorre e as motivações do assassino. O número de vítimas necessário para caracterizar cada um destes crimes possui repercussões importantes para a sociedade pois relaciona-se a investimentos significativos em segurança, saúde e justiça. Não há critérios considerados unânimes para definir cada um desses termos e alguns autores sugerem a necessidade de características mais específicas, um exemplo é a definição de Egger (1984) [27] para o assassino em série, no qual sugere critérios mais detalhados do que os propostos por Ressler (1988) [르], como a necessidade de que as vítimas não possuam um relacionamento com o criminoso; que os 
assassinatos sejam atos compulsivos, e que visam a satisfação de necessidades que foram desenvolvidas através de fantasias.

Os autores Holmes e Burger [29] sugerem subclassificações para os assassinos em série de acordo com a sua mobilidade geográfica, podendo estes ser estáveis ou instáveis. De forma similar, alguns pesquisadores de assassinatos em massa sugerem que esse termo seja empregado apenas para eventos que ocorrem em locais públicos, por um atirador que seleciona seus alvos de forma aleatória, dessa forma, eventos ocorridos em escolas, cinemas ou shoppings não poderiam ser considerados assassinatos em massa []ㅡ.

As várias definições e tipologias usadas para classificar os diferentes tipos de homicídios múltiplos são derivadas principalmente do foco no autor do crime e nos acontecimentos e circunstâncias dos homicídios. Porém, quando fatores situacionais e aleatórios são considerados as classificações podem ser menos uteis.

Conforme ressaltam Gresswell e Holljn [ㅁ] , o principal perigo das classificações reside em aceitar a suposição de que as ações do perpetrador seguiram suas intenções e, em seguida, impor padrões motivacionais onde não existiu nenhum, levando a pressuposições incorretas acerca das motivações e das características psicopatológicas do criminoso.

As informações acerca de assassinatos múltiplos, assassinatos em massa, assassinatos em série e assassinatos relâmpago, provem predominantemente de artigos das décadas de 70 e 80 , período em que o FBI (Federal Bureau of Investigation) deu início ao trabalho de classificação 
de crimes de acordo com suas características, dessa forma, pesquisas com foco nas particularidades do momento em que vivemos são bem-vindas, sendo este um campo para futuros trabalhos.

\section{Considerações finais}

Os crimes com múltiplas vítimas possuem características especificas e os termos assassinato múltiplo, assassinato em massa, assassinato em série e assassinato relâmpago não são intercambiáveis, deste modo, saber quando empregar o termo correto para referir-se a um determinado evento ou perpetrador é essencial. O conhecimento das particularidades de cada um destes atos homicidas e da psicopatologia dos seus perpetradores possibilita aos psiquiatras e aos demais profissionais da saúde que trabalham com estes crimes a detecção e a prevenção de tais eventos. Por fim, faz-se necessária a condução de mais estudos acerca de homicídios múltiplos no Brasil, com o objetivo de conhecermos melhor a realidade brasileira quanto a este tipo de crime. 


\section{Referências}

1. Adelson, Lester. The Pathology of Homicide. Springfield: Charles C Thomas Publisher; 1974.

2. Megargee E, Carbonell Joyce. A Longitudinal Study of Violent Criminal Behavior. Florida: Florida State University; 1993.

3. Brookman F, Maguire E, Maguire M. The Handbook of Homicide. Oxford: John Wiley \& Sons; 2017. https://doi.org/10.1002/9781118924501

4. Douglas J, Burgess A, Burgess A, Ressler R. Crime Classification Manual: A Standard System for Investigating and Classifying Violent Crimes Second Edition. San Francisco: Jossey Bass; 2006.

5. Gresswell D, Holljn C. Multiple Murder. The British J of Crimin. 1994;34:1-14. https://doi.org/10.1093/oxfordjournals.bjc.a048379

6. Douglas J, Ressler R, Burgess A, Hartman C. Criminal Profiling from Crime Scene Analysis. Behavioral Sciences \& the Law. 1986;4:401-421. https://doi.org/10.1002/bsl.2370040405 
7. Knoll IV J, Annas G. Mass Shootings and Mental Illness. In: Gold L, Simon R, editors. Gun Violence and Mental Illness. Arlington: American Psychiatric Association Publishing; 2015. p. 81-104.

8. Kelleher M D.Flash point: the American mass murderer. Westport: Praeger Publishers; 1997.

9. Declercq F, Audenaert K. Predatory Violence Aiming at Relief in a Case of Mass Murder: Meloy's Criteria for Applied Forensic Practice. Behav. Sci Law. 2011;29:578-591. https://doi.org/10.1002/bsl.994 PMid:21748789

10. Myers W, Husted D, Safarik M, O'Toole M. The Motivation Behind Serial Sexual Homicide: Is It Sex, Power, and Control, or Anger? J Forensic Sci. 2006;51:900-7. https://doi.org/10.1111/j.15564029.2006.00168.x - PMid: 16882237

11. Aitken L, Oosthuizen P, Emsley R, Seedat S. Mass Murders: Implications for Mental Health Professionals. Int'l. J. Psychiatry In Medicine. 2008;38:261-269. https://doi.org/10.2190/PM.38.3.C PMid: 19069571

12. Fox J, Levin J. Mass Murder: An Analysis of Extreme Violence. J of Applied Psychoanalytic Studies. 2003;5:47-64. https://doi.org/10.1023/A: 1021051002020 
13. Simon A. Application of Fad Theory To Copycat Crimes:

Quantitative Data Following The Columbine Massacre. Psychological Reports. 2007;100:1233-1244.

https://doi.org/10.2466/pr0.100.4.1233-1244 - PMid:17886511

14. Lee J, Lee TS, Ng BY. Reflections on a Mass Homicide. An Acad of Med. 2007;36:444-447. PMid: 17597973

15. Meloy J, O'Toole M. The Concept of Leakage in Threat Assessment. Behav. Sci. Law 2011;29:513-527. https://doi.org/10.1002/bsl.986 - PMid:21710573

16. Meloy J, Hempel A, Mohandie K, Shiva A, Phil M, Gray B. Offender and Offense Characteristics of a Nonrandom Sample of Adolescent Mass Murderers. J. Am. Acad Child Adolesc Psychiatry. 2011;40:719-28. https://doi.org/10.1097/00004583-20010600000018 - PMid: 11392351

17. Meloy J. Empirical basis and forensic application of affective and predatory violence. Australian \& New Zealand Journal of Psychiatry, 2006;40:539-547. https://doi.org/10.1080/j.14401614.2006.01837.x - PMid:16756578

18. Knoll IV J. Mass Murder: Causes, Classification, and Prevention. Psych Clinics of N America. 2012;35:757-780. https://doi.org/10.1016/j.psc.2012.08.001 - PMid:23107562 
19. Knoll IV J, Ressler R, Hazelwood R, Burgess A. Serial Homicide. Wiley Encyclop of Foren Sciec. 2009:1-9.

https://doi.org/10.1002/9780470061589.fsa308

- 20. Schlesinger L. Sexual homicide: Differentiating catathymic and compulsive murders. Aggression and Violent Behavior. 2007;12:242-256. https://doi.org/10.1016/j.avb.2006.09.007

- 21. Marono A, Reid S, Yaksic E, Keatley D. A Behaviour Sequence Analysis of Serial Killers' Lives: From Childhood Abuse to Methods of Murder. Psychiatry, Psychology and Law. 2020;0:1-12. https://doi.org/10.1080/13218719.2019.1695517 - PMid:32284784 - PMCid:PMC7144278

- 22. Fayet Júnior N, Santos J, Cavedon B. Do Profiling Psicológico Criminal na Identificação de Serial Killers do Gênero Feminino. Porto Alegre: Elegantia Juris; 2019.

23. Barros AJ, Rosa RG, Telles LE, Taborda JG. Attempted Serial Neonaticides: Case Report and a Brief Review of the Literature. J Forensic Sci. 2016;61:280-283. https://doi.org/10.1111/15564029.12873 - PMid:26259153

24. Kellert S, Felthous A. Childhood Cruelty toward Animals among Criminals and Noncriminals. Human Relations 1985;38:1113-1129. https://doi.org/10.1177/001872678503801202 
25. Newton M. The Encyclopedia of Serial Killers, Second Edition. New York: Facts on Life; 2006.

- 26. Lavergne G. A Sniper in the Tower: The Charles Whitman Mass Murders. University of North Texas Press. 1997.

27. Egger, S.A. A Working Definition of Serial Murder and the Reduction of Linkage Blindness. J. of Police Sci and Administ. $1984 ; 12: 348-357$.

28. Ressler R, Burgess A, Douglas, J. Sexual Homicide: Patterns and Motives. New York: Lexington Books; 1988.

29. Holmes R, DeBurger J. Serial Murder. Beverly Hills: Sage; 1988. 


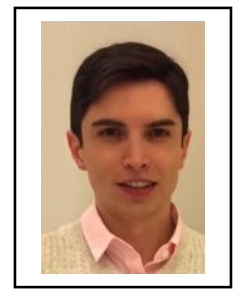

Saulo Maia Martins da Silva

$\underline{\text { ORCID } \quad \text { Lattes }}$

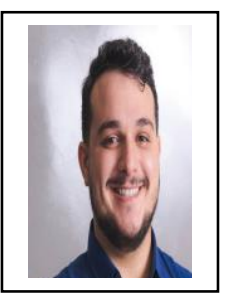

Caio Gibaile Soares Silva

ORCID Lattes

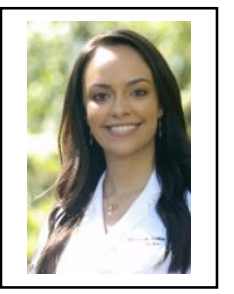

Bibiana de Borba Telles

ORCID Lattes

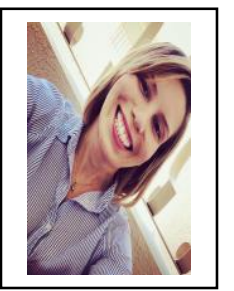

Alcina Juliana Soares Barros

$\underline{\text { ORCID }}$

Lattes

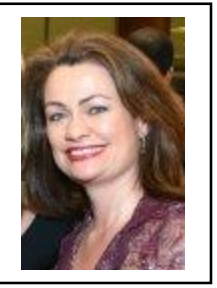

Lisieux Elaine de Borba Telles

ORCID Lattes 